\title{
The segment polarity gene porcupine encodes a putative multitransmembrane protein involved in Wingless processing
}

\author{
Tatsuhiko Kadowaki, ${ }^{1}$ Elizabeth Wilder, ${ }^{1,2}$ John Klingensmith, ${ }^{1,2}$ Kimon Zachary, and \\ Norbert Perrimon ${ }^{3}$ \\ Department of Genetics, Howard Hughes Medical Institute, Harvard Medical School, Boston, Massachusetts 02115 USA
}

The Wnt protein Wingless $(\mathrm{Wg})$ functions as a signal in patterning of both the Drosophila embryo and imaginal discs. Lack of porcupine (porc) activity is associated with mutant phenotypes similar to those of $\mathbf{w g}$ mutations. In porc mutant embryos, $\mathrm{Wg}$ protein is confined to the cells that produce it, suggesting that Porc plays a role in processing or secretion of $\mathrm{Wg}$. porc encodes a novel transmembrane protein that appears to be concentrated at the endoplasmic reticulum. We present both genetic and in vitro evidence demonstrating that porc is involved specifically in the processing of Wg. We identified a human sequence related to Porc suggesting the existence of a family of proteins involved in processing of Wnts.

[Key Words: Drosophila; transmembrane protein; Wingless; porcupine]

Received October 1, 1996; revised version accepted October 30, 1996.

Like its murine homolog, the proto-oncogene Wnt-1, Drosophila wingless ( $w g$ ) encodes a secreted protein that has potent effects on the differentiation of responsive cells (for review see, Klingensmith and Nusse 1994; Siegfried and Perrimon 1994). Wg has been implicated in a number of developmental processes that include embryonic segmentation, gut formation, and imaginal discs patterning. To identify components involved in Wg signaling, a genetic approach has been undertaken. To date, four segment polarity genes, dishevelled (dsh), armadillo $($ arm), zeste-white3 (zw3), and porcupine (porc) have been implicated in $\mathrm{Wg}$ signaling. The current model (for review, see Klingensmith and Nusse 1994; Siegfried and Perrimon 1994; Bhanot et al. 1996; Perrimon 1996) is that $\mathrm{Wg}$, which requires Porc activity to be secreted, interacts with the seven-transmembrane DFz2 receptor to activate a signal transduction pathway that is mediated by Dsh, Zw3, and Arm. This pathway operates in a number of developmental processes and, depending on the cell type, regulates different sets of transcription factors. For example, $\mathrm{Wg}$ signaling regulates engrailed (en) in the embryonic epidermis and genes of the achaete scute complex at the wing margin.

The function of Porc in Wg signaling is not elucidated.

${ }^{1}$ Present addresses: T.K.: Nagoya University, BioScience Center, Chikusa, Nagoya, 464-01 Japan; E.W.: Department of Cell and Developmental Biology, University of Pennsylvania School of Medicine, Philadelphia, Pennsylvania 19104-6058 USA; J.K.: Samuel Lunenfeld Research Institute, Mount Sinai Hospital, Toronto, Ontario M5G 1 X5 Canada.

${ }^{2}$ These authors contributed equally to this work.

${ }^{3}$ Corresponding author.
Embryos that are missing both the maternal and zygotic porc gene product have a cuticular phenotype identical to wg mutant embryos (Perrimon et al. 1989). Interestingly, $\mathrm{Wg}$ has an altered, less diffuse distribution in porc mutant embryos. In wild-type animals, expression studies have shown that $\mathrm{Wg}$ protein is found outside its RNA expression domain. In the embryonic epidermis, Wg protein antibody staining appears punctate because of the accumulation of $\mathrm{Wg}$ in intracellular vesicles. These vesicles are detected both in wg-expressing and neighboring $w g$ nonexpressing cells, and the distribution of these vesicles appears graded on either side of the wg-expressing cells (van den Heuvel et al. 1989; Gonzalez et al. 1991; Couso et al. 1994). In porc mutant animals, Wg appears to be confined to the expressing cells, and is very stable (van den Heuvel et al. 1993; Siegfried et al. 1994), suggesting that porc encodes a product required for secretion, processing or normal diffusion of $\mathrm{Wg}$.

The function of porc in $\mathrm{Wg}$ paracrine signaling has been examined previously with the paradigm of en regulation by Wg. In the embryonic epidermis, at stage 10, $\mathrm{Wg}$ is required for maintenance of en transcription (DiNardo et al. 1988; Yoffe et al. 1995). In mutants such as $d s h$ that block the reception of $\mathrm{Wg}$ signal in the receiving cells, En expression fades (Manoukian et al. 1995). Subsequently, wg expression decays (Martinez-Arias et al. 1988). This was proposed to be a secondary result of the decay of en expression, because En is required for the maintenance of $w g$ expression. In contrast to $d s h \mathrm{mu}-$ tants, porc and wg mutant embryos exhibit decay of $w g$ mRNA prior to the disappearance of En protein at stage 9 (Manoukian et al. 1995). This observation, as well as 
others (Bejsovec and Wieschaus 1993; Hooper 1994), revealed the existence of a $\mathrm{Wg}$ autoregulatory pathway that operates, in addition to Hedgehog $(\mathrm{Hh})$ signaling, to maintain $w g$ expression. These results suggested that Porc and $\mathrm{Wg}$ activities are intimately linked and distinguished Porc function in Wg signaling from components such as Dsh, Arm, and Zw3 that mediate Wg paracrine activity in receiving cells (Manoukian et al. 1995).

To gain additional insights into Porc function, we have determined the cellular requirement for porc gene activity and examined the effect of porc mutations on other Wg-mediated developmental processes. Our results are consistent with the model that porc encodes a factor involved in $\mathrm{Wg}$ processing. We have identified the porc gene product and found that it encodes an evolutionarily conserved putative multi-transmembrane protein that primarily localizes to the endoplasmic reticulum (ER) and affects $\mathrm{Wg}$ processing in cultured cells.

\section{Results}

porc acts nonautonomously in Wg patterning of the embryonic epidermis

Embryos devoid of both maternal and zygotic porc gene activity, referred to as porc embryos, die before hatching with a segment polarity phenotype indistinguishable from that of wg mutants (Fig. 1B). If Porc is involved in
Wg secretion (see Introduction) then it should act like Wg nonautonomously in the formation of naked cuticle (Lawrence et al. 1994). We generated large patches of porc mutant tissue in the embryo using an unstable ring- $X$ chromosome (Zalokar et al. 1980). Genotypically porc mutant tissues were recognized by use of the $\mathrm{X}$-linked cell autonomous marker shavenbaby (svb), which decreases the number and size of denticles (Fig. 1C). Genetically porc mutant cuticles were found to secrete denticles in either the wild-type or segment polarity configuration (Table 1; Fig. 1D) indicating that porc acts nonautonomously in $\mathrm{Wg}$ signaling. The extent of nonautonomy observed with porc is comparable to the nonautonomy observed in wg genetic mosaics /see Discussion).

porc is required for Wg-mediated patterning in the imaginal discs and acts nonautonomously

To determine whether the relationship of porc to $w g$ extends to other developmental contexts, we investigated the phenotypes of porc in imaginal development. Although porc hemizygotes derived from heterozygous mothers usually die as late larvae, a few survive through metamorphosis before dying. porc mutant adults display a variety of defects relative to wild type. Their wings are nicked and lack marginal bristles (Fig. 2B), they lack an-
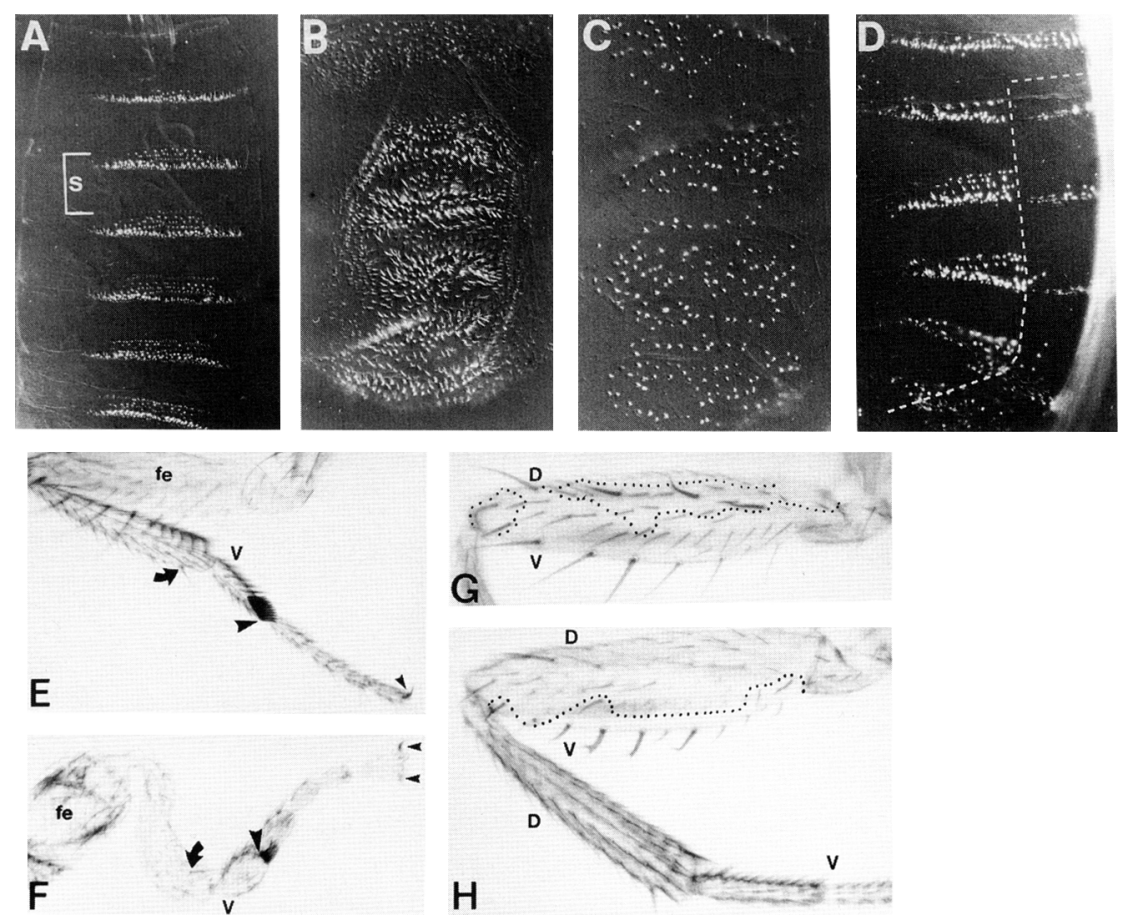

Figure 1. Phenotype and nonautonomy of porc mutations. (A) Wild-type embryo. The segmental pattern is reflected by belts composed of several rows of denticles spanning the anterior portion of each segment $(S) .(B)$ A porc mutant embryo with an extreme wg-like segment polarity phenotype. $(C)$ $s v b$ porc embryo. The denticle marker $s v b$ decreases the size and number of denticles, but does not interfere with the segment polarity phenotype. (D) Gynandromorphic $s v b$ porc ${ }^{P B 16} /$ ring-X embryo. A porc mutant territory, marked with $s v b$, sometimes develops a wild-type pattern revealing that porc encodes a cell nonautonomous function. In this example, the middle of the embryo is bisected by the line of mosaicism (dotted line), but the denticle belts on both sides are in wild-type configuration. In the posterior, denticles are $s v b$ and in a segment polarity pattern. Structure of a wildtype $(E)$ and porc $/ Y(F)$ prothoracic male leg. The femur (fe), sex combs (large arrow head), dorsal subapical bristle of the tibia (curved arrow), and claws (small arrow head) are indicated. Note that the porc mutant leg is bulbous and truncated, the claw is duplicated, and the number of sex combs is reduced to 1-3. No bristles characteristic of ventral $(\mathrm{v})$ pattern occur anywhere in the leg. $(G, H)$ Large clones of porc ${ }^{P B 16}$ mutant cells occurring in otherwise wild-type (heterozygous) females. $(G) f$ porc dorsal clone, prothoracic leg. A large mutant porc clone occurs in dorsal and dorso-lateral tissue of the femur, outlined by a dotted line. No pattern abnormality results. $(H) f$ porc ventral clone, prothoracic leg. A large porc clone extends along the ventral edge of the femur but pattern is wild type. The clone is outlined by a dotted line. The yellow bristles above it are its twin spot (sister clone) and are wild type. 
Table 1. Mosaic analysis of porcupine

\begin{tabular}{|c|c|c|c|c|c|c|}
\hline Cross & Progeny & Total & Mosaic & Autonomy & Nonautonomy & Ambiguous \\
\hline \multicolumn{7}{|l|}{ Embryonic gynanders } \\
\hline$F M 7 / s v b \times \operatorname{ring} X / Y$ & svb/ring $X$ & 62 & 9 & 6 & 0 & 3 \\
\hline GLC $s v b$ porc $\times \operatorname{ring} X / Y$ & svb porc/ring $X$ & 135 & 13 & 1 & 9 & 3 \\
\hline \multicolumn{7}{|l|}{ Adult gynanders } \\
\hline FM $7 / y$ w $f$ porc $\times$ ring $X / Y$ & FM7/ring $X$ & 225 & 21 & 15 & 0 & 6 \\
\hline$F M 7 / y$ w f porc $\times$ ring $X / Y$ & $y w$ fporc/ring $X$ & $?^{\mathrm{a}}$ & 18 & 2 & 16 & 0 \\
\hline
\end{tabular}

Animals showing marked and unmarked tissue (mosaic), were evaluated for autonomy or nonautonomy. Some mosaics were ambiguous: in embryos because mosaic borders could not be seen, and in adults because of cell death or lack of scorable phenotype. Two alleles, porc ${ }^{P B 16}$ and porc ${ }^{i 8}$, were used for these studies.

${ }^{a}$ Some gynandromorphs died before making adult structures, so the total number of $y w$ fporc/ring $X$ is unknown.

tennal structures, and tergites are incomplete (not shown|. Defects are observed along the proximo-distal axis: The legs are shortened with tarsal segments reduced in size and number, the claws are often missing but, when present, are often duplicated (Fig. 1F). The dorsal-ventral axis is also severely affected in porc mutant discs: Ventral pattern elements are missing and are replaced by duplications of dorsal structures. These phenotypes are reminiscent of those exhibited by $w g$ imaginal disc mutant phenotypes (Couso et al. 1993; Phillips and Whittle 1993).

To analyze these phenotypes in the discs, we examined the expression of genes that are known to be regulated by $\mathrm{Wg}$. In the wing disc, $w g$ is required early for formation of the wing and later for the specification of bristles around the wing periphery (Couso et al. 1993; Phillips and Whittle 1993). During this late phase, wg signaling results in the specification of sensory mother cells on either side of the dorsal-ventral border in the anterior compartment. These cells give rise to the innervated bristles of the anterior margin and express the gene neuralized (neu) (Usui and Kimura 1992; Fig. 2C). Expression of this gene is not seen in this region of porc discs (Fig. 2D). Similarly, expression of cut marks the dorsal-ventral border of the late third instar wing disc (Fig. 2E), depends on wg activity (Couso et al. 1994), and is missing in porc mutant discs (Fig. 2F).

In the leg discs, $w g$ is expressed ventrally where it is required for the specification of ventral structures (Struhl and Basler 1988). In addition, $\mathrm{Wg}$ protein in the

Figure 2. Analysis of porc function in the wing disc. The Drosophila wing $(A)$ exhibits characteristic bristles around its periphery, that are dependent on $w g$ function during the late third instar. The bristles of the anterior margin (bracket) are the most easily seen. In porc hemizygotes $(B)$, these bristles are missing; in addition, notches form, which are also characteristic of loss of $w g$ function. Expression of neu $(C, D)$ or cut $(E, F)$ in wild-type $(C, E)$ or porc/ $Y(D, F)$ wing discs. In wild type, neu-expressing sensory mother cells are found in two rows (arrows in C). Expression of neu at the margin is missing in porc/Y wing discs. Similarly, wg is required for cut expression at the margin (E, arrows), which is missing in porc hemizygotes $(F)$. For each of these experiments, wandering third instar male larvae were separated from females and stained. Approximately half exhibited loss of cut expression; approximately half of the males carrying the $A 101$ enhancer trap exhibited the pattern of neu expression shown here. In each disc, ventral is up and anterior is to the left.
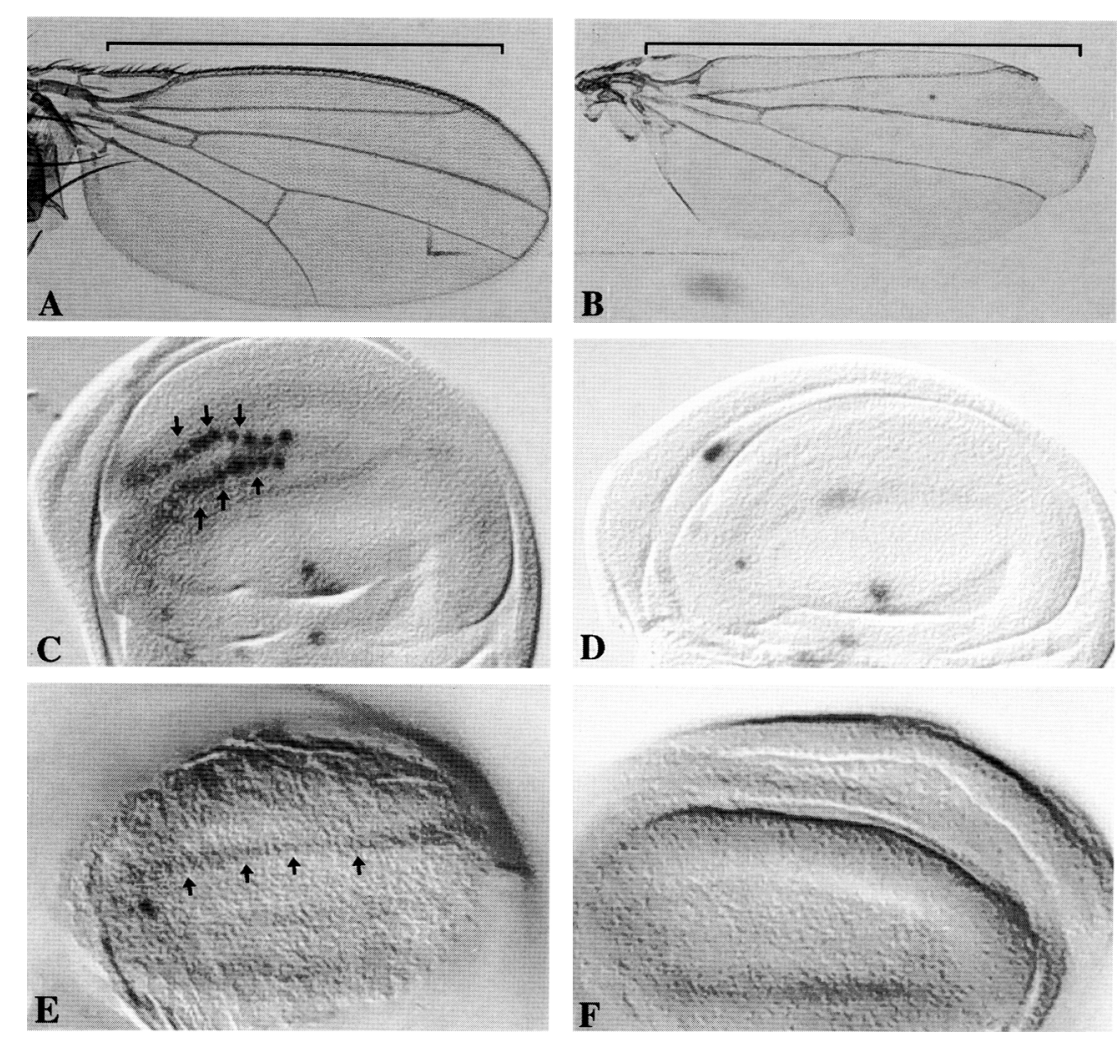
disc center is required for organization of the proximaldistal axis. The enhancer-trap line P1394 (E.L. Wilder, unpubl.) expresses $L a c Z$ in cells at the center of the leg discs and also in a dorsal arc of cells (Fig. 3A). This pattern of expression is similar to that of aristaless (al) and, like $a l$, responds to the combined signals of $w g$ and $d e-$ capentaplegic (dpp; Campbell et al. 1993; E.L. Wilder, unpubl.). Expression of this gene is lost in the center of porc mutant discs, and the dorsal arc is duplicated ventrally (Fig. 3B). This suggests that porc is required for $w g$ function in both proximal-distal and dorsal-ventral pattern specification. The requirement for porc in proximaldistal pattern is confirmed by the aberrant expression of apterous (ap) in mutant discs (Fig. 3C,D). Lack of expression of the ventral marker $H 15$ (Brook et al. 1993) in porc mutant discs shows that porc is necessary for $w g$ function in these cells (Fig. 3E,F). These cells are transformed to dorsal fates, as is shown by the duplication of the dorsal proneural cluster that expresses neu (Fig. 3G,H).

Because porc acts nonautonomously in the embryonic epidermis, we tested whether it also functions nonautonomously in Wg-mediated patterning of the imaginal discs. Two kinds of mosaics were generated. First, marked mitotic clones of cells lacking porc activity were induced in first-instar larvae. These clones appeared at the same frequency as control clones and never gave rise to pattern abnormalities (not shown). Even in the leg, in which porc is required for ventral patterning, ventral clones as well as lateral and dorsal clones (Fig. 1G,H) appear wild type. Second, by use of ring-X instability to generate adult porc gynandromorphs, we examined the structures produced in mosaic animals (Table 1). We observed occasional rescue of adult structures affected in porc mutant, but only if wild-type tissue occurred nearby. Thus, studies in the imaginal discs support the conclusions obtained from the embryonic mosaics that porc acts nonautonomously in $w g$ patterning.

porc encodes a putative transmembrane protein that is concentrated at the $E R$

Ferrus et al. (1990), in their characterization of the Shaker region, conducted a chromosomal walk that $\mathrm{ex}^{-}$ tended to the proximal region of $D p(1 ; 3) / C 153$. This duplication covers porc, and previous genetic analysis of the region indicated that porc is located near this breakpoint (Eberl et al. 1992). Using RFLP mapping, we defined approximately the genomic position of the porc gene (Fig. 4; Materials and Methods for details). Northern analyses revealed the presence of four transcription units in the presumptive porc region. Southern blot analyses allowed us to precisely map the proximal breakpoint of $D p(1 ; 3) / C 153$ and identify a DNA alteration associated with the gamma-rays induced porc ${ }^{G 18}$ allele. Results from these experiments identified the $2.2 / 2.4-\mathrm{kb}$ transcripts as the most likely candidates for porc. A 2.4$\mathrm{kb}$ cDNA was isolated and a number of data obtained to show that this cDNA encodes porc. First, a sense RNA prepared from this cDNA was able to rescue the segment polarity phenotypes of porc mutant embryos derived

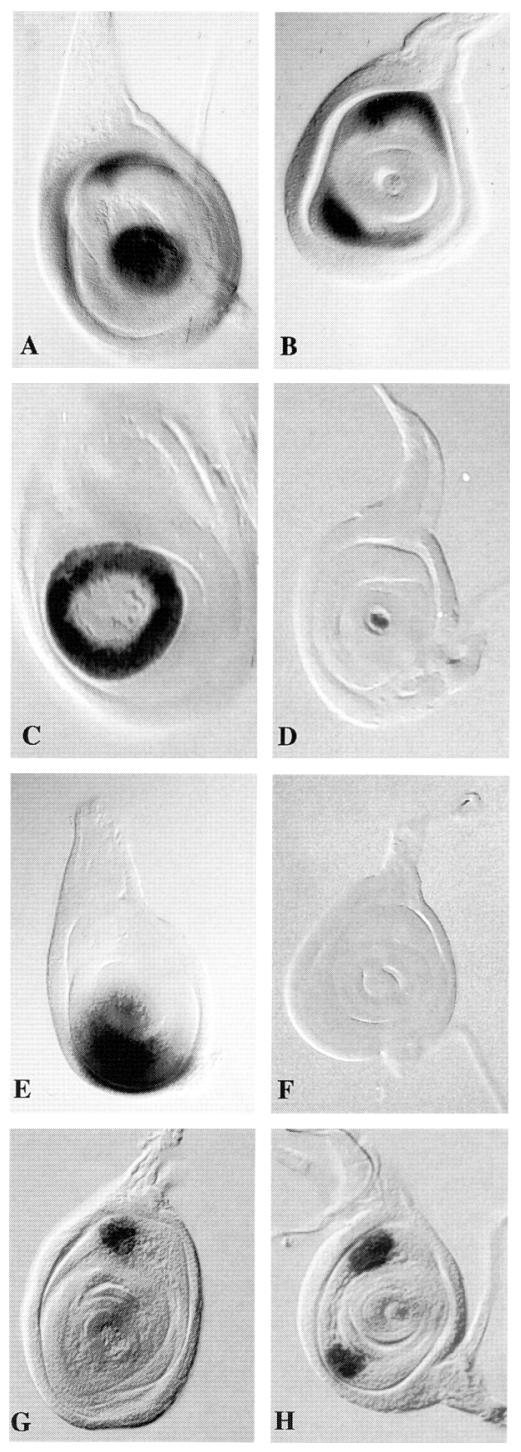

Figure 3. Analysis of porc function in the leg disc. Expression of $L a c Z$ from the $P 1394$ enhancer trap line $(A, B)$, ap Lac $Z(C, D)$, $H 15(E, F)$, or neuLacZ $(G, H)$ was examined by X-Gal staining in wild type $(A, C, E, F)$ or porc/Y $(B, D, F, H)$ leg discs. LacZ in $P 1394$ $(A)$ is expressed at the disc center in a manner that responds to the combined activities of $w g$ and $d p p$ (not shown). In addition, it is expressed in a dorsal cap. The center domain of expression is missing in porc hemizygotes $(B)$ and the dorsal cap is duplicated ventrally. In wild-type leg discs, $a p$ is expressed in a ring that includes the presumptive tarsal leg segments $(C)$. In porc mutant discs $(D)$, this ring collapses to a central dot. Occasionally, expression is entirely absent. The ventral/anterior region of wild-type leg discs express the H15 marker $(E)$ that is entirely missing in porc mutant discs $(F)$. The dorsal cluster of proneural cells that express neu $(G)$ is duplicated in the ventral region of porc $/ Y$ discs $(H)$. Together, these data show that porc is required for $w g$ function in both proximal-distal and dorsal-ventral pattern specification.

from germ-line clones (see Materials and Methods for details). Second, this $2.4-\mathrm{kb}$ cDNA driven by the heat 

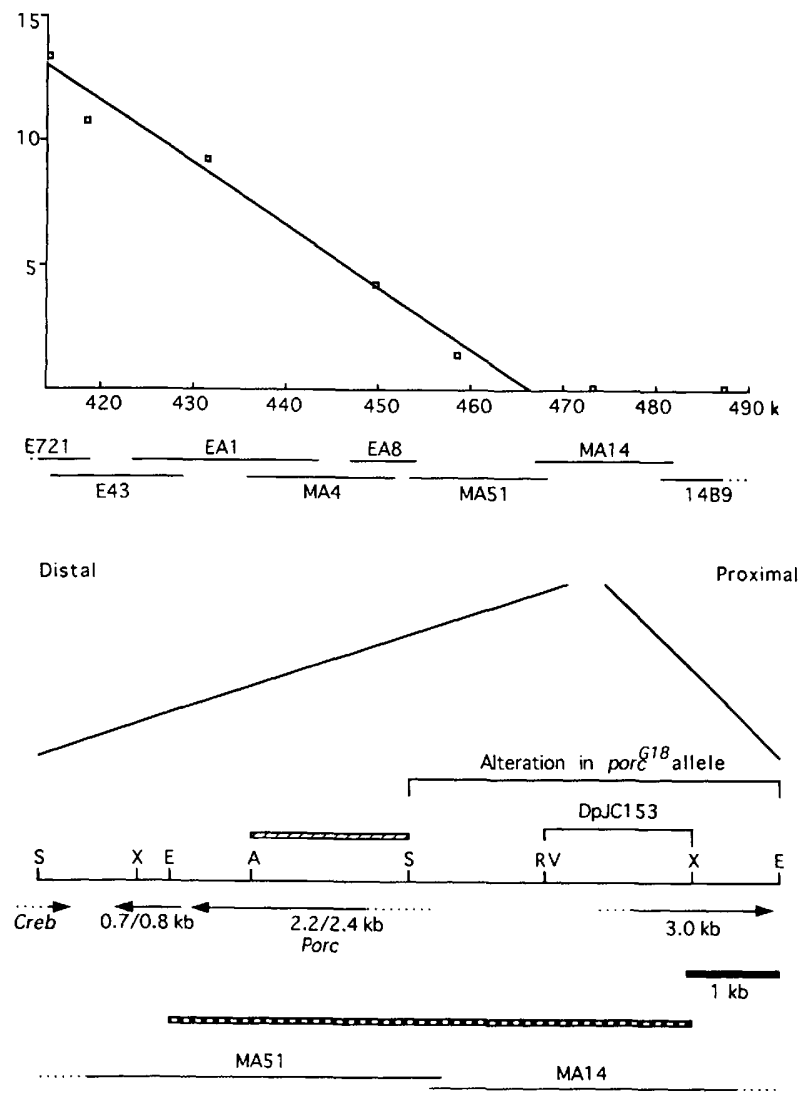

Figure 4. Molecular characterization of the porc gene. RFLP analysis of 15 recombination events that occurred between os and porc chromosomes is shown. The $\mathrm{x}$-axis indicates the physical distance and the $y$-axis represents the number of recombinants carrying the RFLP pattern of the porc chromosome. No recombinants with porc RFLP were found beyond $470 \mathrm{~kb}$. The approximate position of the porc locus is determined by the intersection of the linear line with the $\mathrm{x}$-axis. A genomic DNA fragment covered by each phage is shown below the graph. The region around $466 \mathrm{~kb}$ is shown in detail. Four transcripts were identified and the 2.2- and 2.4-kb mRNA were determined to encode a porc transcript based on the location of DNA alteration in porc ${ }^{618}$ allele and the position of the $D p(1 ; 3) / C 153$ breakpoint. The striped and hatched bar indicates a DNA fragment used for a screening of cDNA library and P-element transformation, respectively. (S) SacI; (X) XbaI; (E) EcoRI; (A) AccI; (RV) EcoRV.

shock promoter was able to rescue porc mutants. Finally, a 5-kb genomic fragment that covers this cDNA was able to rescue porc mutants. Both a 2.2- and 2.4-kb RNA are detected in 0-3 hr embryos with porc antisense RNA probe (not shown). The $2.4-\mathrm{kb}$ transcript is present throughout development and the 2.2 -kb transcript is maternal-specific. In situ hybridization shows that porc is uniformly expressed in embryos (data not shown).

porc encodes a protein of 525 amino acids with a predicted molecular mass of $59 \mathrm{kD}$ (Fig. 5). There is a cluster of acidic amino acids at the amino terminus, otherwise the rest of the sequence is hydrophobic. Based on the results of the three algorithms (Kyte and Doolittle 1982;
Eisenberg et al. 1984; Rao et al. 1986) for prediction of transmembrane domains, Porc appears to possess at least eight transmembrane domains and possibly two more. It appears that Porc has no cleaved signal sequence and that its amino terminus is located outside the cytosol (Hartmann et al. 1989). The hydrophilic region between each transmembrane domain of Porc is quite small (three amino acids in one case) and it does not have any cellular signaling domains (for example, kinase and G proteinbinding domains). These results suggest that Porc may form a pore that facilitates transport of molecules across the membrane (Unwin 1989; Griffith et al. 1992). Because many transport proteins have 12 membrane-spanning domains (Henderson 1993), Porc may form the pore by self-assembly or association with other transport proteins. It also lacks the ATP-binding cassette that is characteristic of ABC transporter (Ashcroft and Roper 1993).

Searches through available data bases identified one human sequence, MG61, with striking similarities to Porc. MG61 was isolated from a human retina cDNA library (Nathans et al. 1986) and exhibits $37 \%$ identity with Porc (Fig. 5). Porc and MG61 share more homology in the carboxyl terminus than in the amino terminus and most strikingly exhibit a similar structure based on the Kyte-Doolittle hydrophobicity plot.

To determine the intracellular localization of Porc, we attempted to generate polyclonal antibodies against Porc. Because of their low titers and relatively low affinities, they could not detect the endogenous Porc in embryos. To circumvent this problem, we expressed an epitope-tagged (HA) Porc in Kc cells (see Materials and Methods) in which the epitope was inserted at position 110 of the Porc protein. The Porc-HA construct was functional because it could rescue porc mutant embryos following RNA injection in porc mutant embryos derived from germ-line clones (not shown). Immunofluorescent detection of Porc-HA in the transfected Kc cells shows that it is primarily localized in a reticular perinuclear region, the ER (Fig. 6). The same subcellular localization was also observed when the HA tag was inserted at position 28 of the Porc protein (not shown). These two epitopes are localized at either the amino or carboxyl terminus of the first transmembrane domain. If Porc is localized at the plasma membrane, the HA antibody should be accessible to either one regardless of the membrane topology of Porc. However, we found that cell permeabilization was necessary to detect both proteins, indicating that no, or little, Porc localizes to the plasma membrane. In addition, the HA epitope-tagged Porc expressed in mouse $3 \mathrm{~T} 3$ cells also colocalized with the ER luminal protein, BiP, by double staining (not shown). These results altogether suggest that Porc appears to concentrate at the ER of both Drosophila and mammalian cells.

\section{Porc modifies Wg processing in cultured cells}

Because the phenotypic analysis of porc mutants suggests that Porc is involved in $\mathrm{Wg}$ processing or secretion, we tested the roles of Porc on Wg processing in vitro 

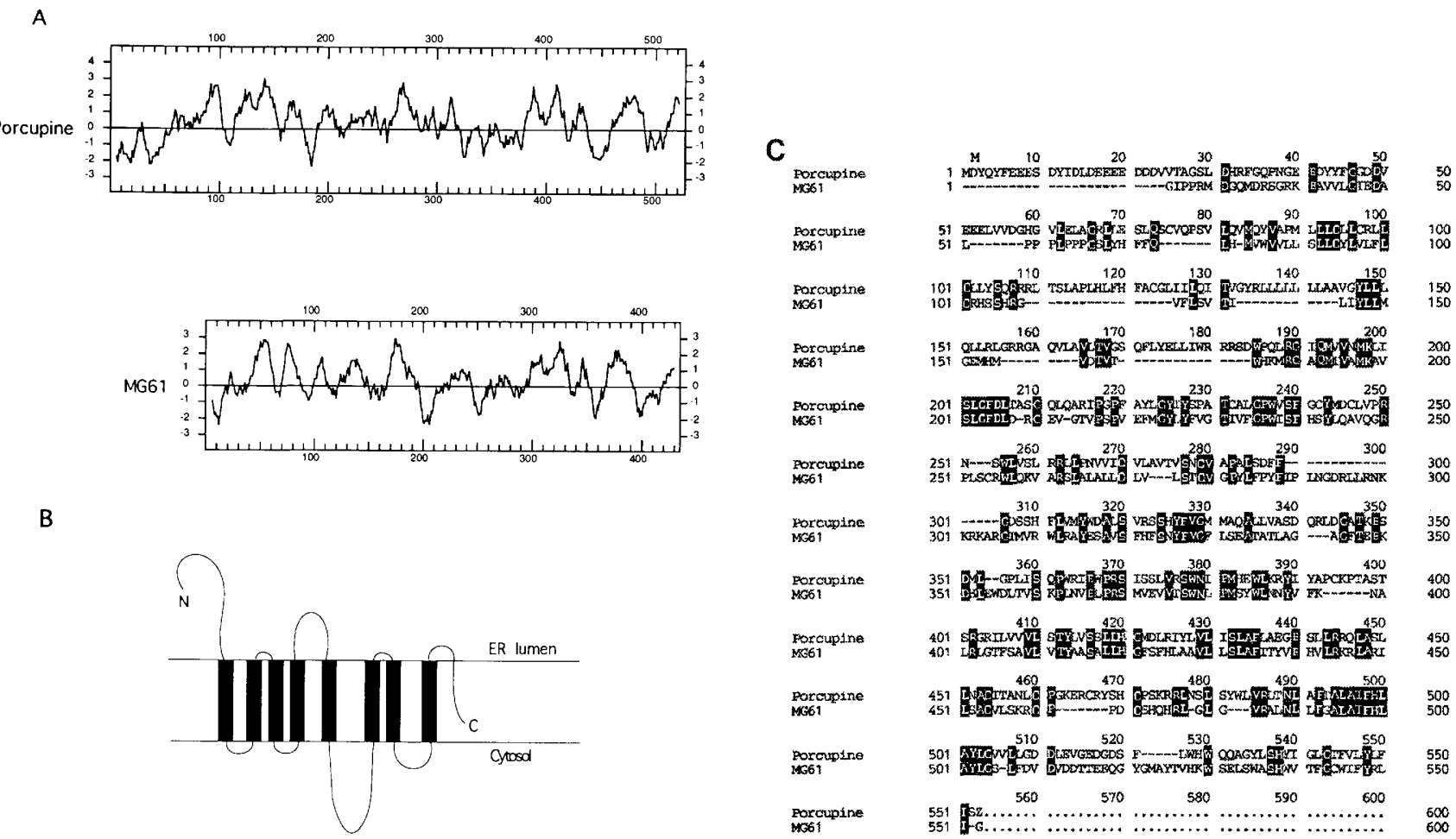

Figure 5. Sequence and structure of Porc and MG61. (A) Analyses of Porc and MG61 amino acid sequences with the Kyte-Doolittle hydrophobicity plot suggests that both Porc and MG61 have similar structures and contain at least eight transmembrane domains. $(B)$ The putative structure of Porc is shown. The amino terminus is likely to be facing the ER lumen based on the charge difference surrounding the first transmembrane domain. $|C|$ The alignment of Porc and MG61 amino acid sequence is shown. Regions of amino acid identities between the two proteins are indicated by black boxes.

with Kc cells that express a low level of endogenous Porc (not shown). Kc cells were transfected with either $H S-W g$ alone or $H S$-Wg and HS-Porc followed by Wg detection in the cell lysate and medium in the presence of suramin. As shown in Figure 7A, three forms of Wg (I, II, and III) are detected in the lysates of cells transfected with $H S$-Wg at 0.5 or $3.0 \mathrm{hr}$ after heat induction. In the lysates of cells transfected with both $H S-W g$ and HS-Porc, three Wg forms are detectable at $0.5 \mathrm{hr}$, but forms I and II almost disappear at $3.0 \mathrm{hr}$ after heat induction. In addition, the largest form of $\mathrm{Wg}$, form IV, is specifically detected in these cells. The forms II and III are detected in the medium of cells expressing $\mathrm{wg}$ alone, whereas only form III is found in the medium of cells expressing both $\mathrm{wg}$ and porc. The total amount of $\mathrm{Wg}$ secreted in the medium may not be changed significantly by ectopic Porc. Focusing on the form III (an endogenous form of $\mathrm{Wg}$ found in embryos), it is secreted more by cells expressing both $w g$ and porc than by cells expressing wg alone (Fig. 7A) because of its enhanced synthesis. The same results were obtained by pulse labeling the transfected cells with $\left[{ }^{35}\right.$ S]methionine followed by chase, as shown in Figure 7B. More Wg forms III and IV are detected in the lysates of cells expressing both $w g$ and porc. The forms of $\mathrm{Wg}$ secreted in the medium after a 3 -hr chase are the same as above. Although more radioactivity (1.5-fold) of form III $\mathrm{Wg}$ is found in the medium of cells expressing both wg and porc compared with cells expressing wg alone, the total level of radioactivity of $\mathrm{Wg}$ detected in the medium is constant. These results suggest that Porc modifies Wg processing but does not significantly increase the total level of secreted $\mathrm{Wg}$ by Kc cells.

To further analyze the roles of Porc on Wg processing, we examined post-translational modifications of $\mathrm{Wg}$. First, the transfected cells were treated with tunicamycin which inhibits $\mathrm{N}$-linked glycosylation. Only form I is synthesized in the presence of tunicamycin irrespective of Porc, suggesting that form I is a precursor whereas others are N-linked glycosylated products (Fig. $7 \mathrm{C}$ ). Second, the type of $\mathrm{N}$-glycans associated with $\mathrm{Wg}$ was analyzed by EndoH, which specifically cleaves high mannose-type $\mathrm{N}$-glycans synthesized in the ER. As shown in Figure $7 \mathrm{D}$, all forms, with the exception of form I, are sensitive to EndoH, suggesting that forms II-IV contain high mannose-type N-glycans. There is another weak band (migrating between forms II and III) in addition to form I in EndoH-treated samples, suggesting that a small fraction of forms III and possibly IV may also have EndoH-resistant N-glycan. Because, as described above, more forms III and IV are synthesized in the presence of ectopic Porc (Fig. 7A-D), these results show that Porc stimulates the processing of $\mathrm{Wg}$ intermediates (forms I and II) as indicated by enhanced addition of high mannose-type $\mathrm{N}$-glycan. The same experiment was also car- 
Figure 6. Immunolocalization of epitope-tagged Porc in Kc cells. The HA epitope-tagged Porc (Porc-HA) is expressed in Kc cells and detected by an epitope-specific monoclonal antibody, 12CA5. The staining pattern indicates that Porc concentrates at the ER. The corresponding DNA staining and phase images are also shown. Porc also colocalizes with the ER luminal protein, BiP, when expressed in mouse 3T3 cells (not shown).
Porc-HA
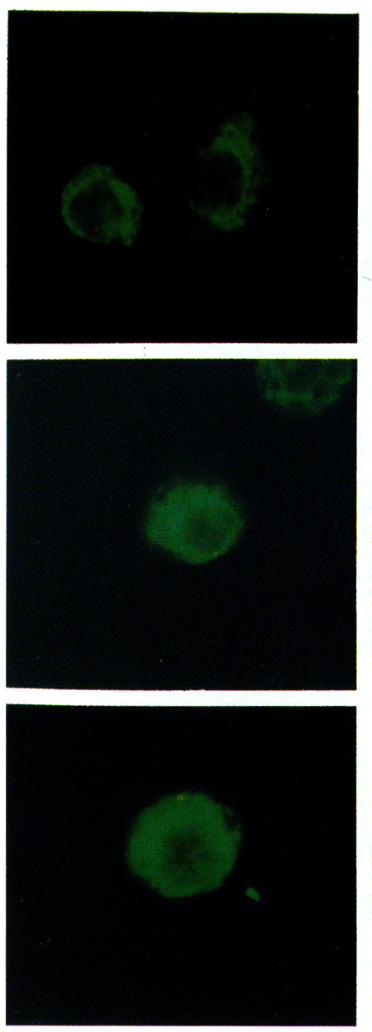

DNA
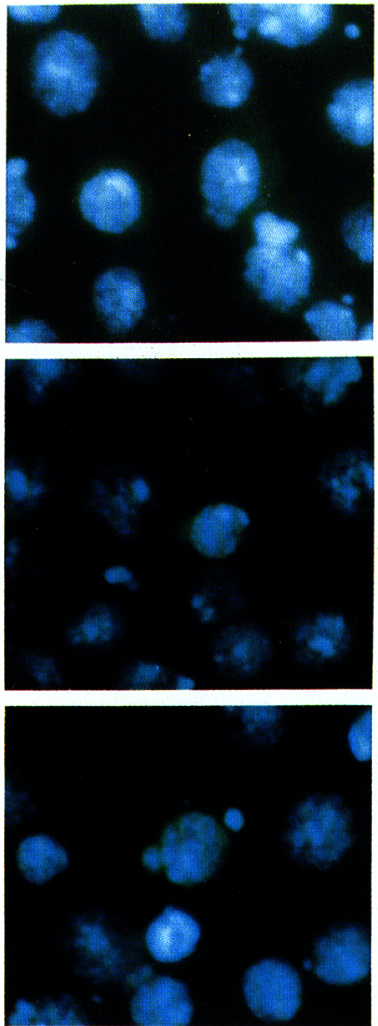

Phase
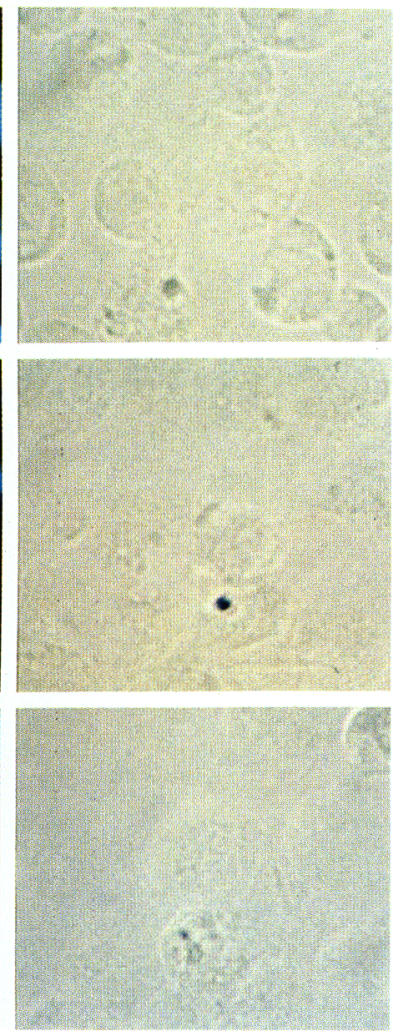

ried out with a wg construct in which the amino-terminal signal sequence was deleted. The processing of this Wg mutant is not modified by Porc, suggesting that it is involved in $\mathrm{Wg}$ processing along the secretory pathway (Fig. 7A). Our data are consistent with the in vivo data of L. Smith, X. Wang, and S. Cumberledge (in prep.), who found that in porc mutant animals, Wg glycosylation is abnormal.

Wg signaling in the midgut, but not Dpp or Hh signaling, is affected in porc mutant embryos

If porc encodes a protein involved in $\mathrm{Wg}$ processing, it raises the issue of its specificity because one may expect molecules involved in secretory mechanisms to be pleiotropic (see Discussion). We examined the role of Porc on midgut formation because it involves signaling from both Wg and the TGF beta-like secreted factor Dpp. Both genes are involved in an inductive cascade leading to formation of the second midgut constriction (Immergluck et al. 1990; Reuter et al. 1990). Wg and Dpp are transcribed in visceral mesoderm cells and regulate the expression of the nuclear homeotic protein Labial (Lab) in the adjoining endoderm. Although both $w g$ and $d p p$ mutants entirely lack the second constriction, their effects on Lab are different. dpp mutants have no Lab ex- pression in the endoderm (Immergluck et al. 1990; Reuter et al. 1990), whereas wg mutants express Lab in an abnormal pattern (Immergluck et al. 1990).

We found that porc mutants lack the second midgut constriction (not shown). Moreover, Lab is expressed in porc mutant embryos, derived from germ-line clones, and the staining pattern is the same as in embryos mutant for wg $^{I N 67}$ (not shown), a Wg secretion defective allele. Rather than a gradient with heaviest staining at the posterior of the domain, Lab antigen in $w g$ mutants is not graded. These results suggest that Dpp signaling does not require porc gene activity.

Further support of the specificity of Porc in Wg signaling comes from examination of the imaginal phenotypes associated with porc pharate adults. As shown in Figures $1-3$, these animals exhibit defects reminiscent to defective $\mathrm{Wg}$ signaling only. If Porc was required for secretion of other secreted molecules involved in imaginal patterning, such as Dpp and $\mathrm{Hh}$, we would expect porc mutant discs to exhibit defects along their antero-posterior axis as well (Zecca et al. 1995). Finally, the effect of Porc on $\mathrm{Hh}$ processing and secretion was also tested by use of cultured cells. The processing and secretion of $\mathrm{Hh}$ expressed in Kc cells is not affected by Porc (Fig. 8). Thus, Porc is not involved in $\mathrm{Hh}$ processing in vitro, which is consistent with the in vivo data that implicate Porc as a component of $\mathrm{Wg}$, but not $\mathrm{Hh}$, signaling pathway. 
A

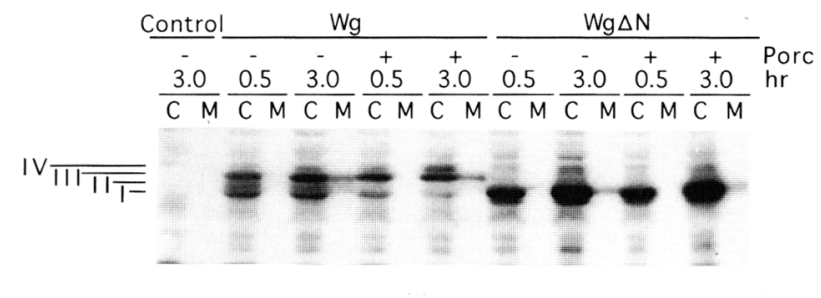

B

C
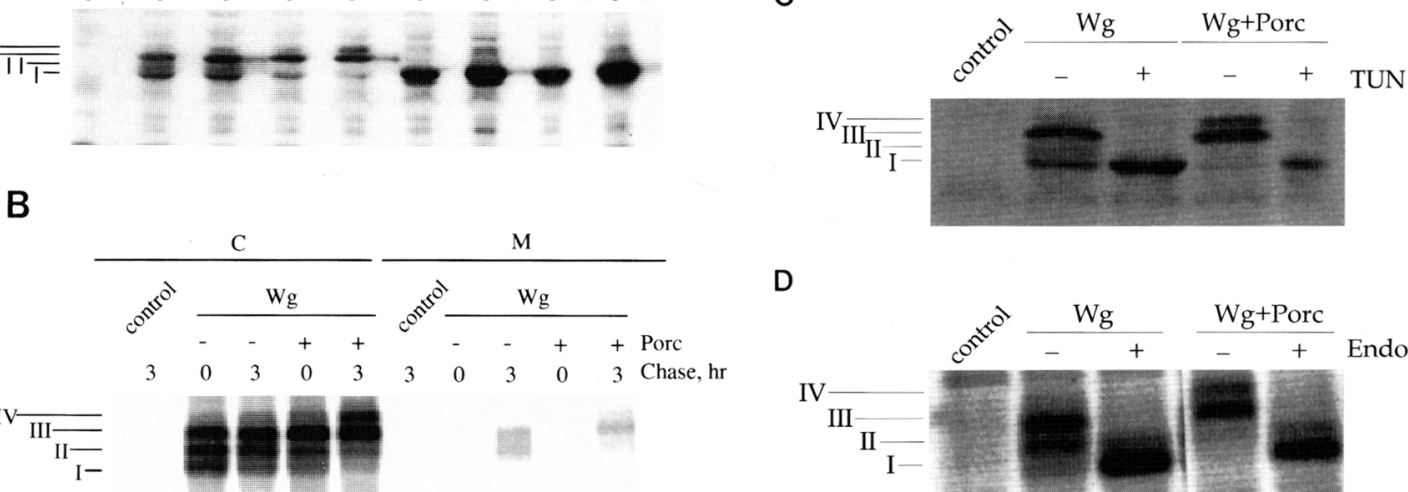

D

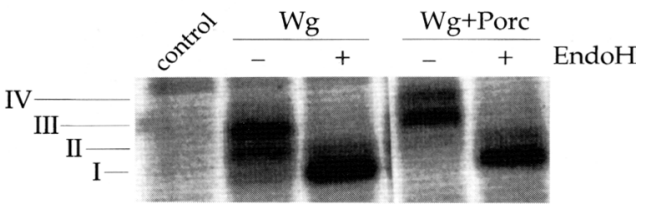

Figure 7. Effect of Porc on $\mathrm{Wg}$ processing. $(A) \mathrm{Wg}$ protein in the cell lysate $(C)$ and medium $(M)$ at 0.5 and 3.0 hr after heat shock was analyzed by Western blot by use of anti-Wg antibody. The overexpression of Porc following cotransfection with hs-porc is indicated by - and + . Control, $\mathrm{Wg}$, and $\mathrm{Wg} \Delta \mathrm{N}$ (Wg lacking amino-terminal signal sequence) indicate the cells transfected with heat shock plasmid, $h s-w g$, and $h s-w g \Delta N$, respectively. Wg forms I-IV are also shown at the left. The processing of Wg does not significantly change during a recovery time of $2.5 \mathrm{hr}$ at $25^{\circ} \mathrm{C}$ in cells expressing wg alone but is stimulated by coexpression of porc. In addition, more $\mathrm{Wg}$ forms III and IV are detected in the medium and cell lysate of cells expressing both $\mathrm{wg}$ and porc, respectively. porc does not have any effect on $\mathrm{Wg} \Delta \mathrm{N}$. One-tenth volume of cell lysate and half volume of medium was subjected to $10 \%$ SDS-PAGE. The medium contained $0.5 \mathrm{~mm}$ suramin to release $\mathrm{Wg}$ from the cell surface and extracellular matrix. $(B)$ The processing (cell lysate, $\mathrm{C}$ ) and secretion (medium, M) of Wg was analyzed by pulse-labeling the transfected cells by heat shock plasmid (control) or hs-wg (Wg) with [ $\left.{ }^{35} \mathrm{~S}\right] \mathrm{me}-$ thionine followed by 0 - and 3 -hr chase. The overexpression of Porc by hs-porc is indicated by - and + . The same results are observed as in $A$ by this analysis. After 3 -hr chase, the radioactivity of forms II and III in the medium of cells expressing wg alone is comparable to that of form III in the medium of cells expressing both $w g$ and porc, although 1.5 -fold more radioactivity of form III is detected in the presence of ectopic Porc. (C) The effect of tunicamycin (TUN) on Wg synthesized in Kc cells transfected with either hs-wg (Wg) or both $h s-w g$ and $h s$-porc (Wg + Porc) is examined by Western blot. Form 1 is produced in the presence of tunicamycin irrespective of Porc, suggesting that it is a precursor and that the others are modified by N-linked glycosylation. $(D)$ The EndoH sensitivity of various $\mathrm{Wg}$ forms in $\mathrm{Kc}$ cells transfected as in $C$ is analyzed by $\left[{ }^{35} \mathrm{~S}\right]$ methionine labeling followed by immunoprecipitation. The forms II-IV are sensitive to EndoH, indicating that they contain high mannose-type $\mathrm{N}$-glycans. The presence of additional weak band in the EndoH-treated samples suggests that a small fraction of forms III and possibly IV may also have EndoH-resistant N-glycans.

\section{Discussion}

porc is involved in Wg signaling

A number of data strongly support the model that Porc is specifically involved in $\mathrm{Wg}$ signaling. First, lack of porc activity results in phenotypes remarkably similar to those of $w g$ both during embryonic as well as imaginal patterning. Embryos that lack both maternal and zygotic porc activity exhibit loss of en expression and cuticular patterning defects that mimic $w g$ mutant embryos. Similarly, porc and $\mathrm{wg}$ cmbryos have identical phenotypes in the embryonic midgut. porc is also required for $\mathrm{Wg}$ signaling during imaginal disc patterning as shown by the expression of specific markers in developing discs and phenotypes of the resulting cuticular derivatives.

Mosaic analyses of porc in the embryo as well as in the imaginal discs reveal that porc acts nonautonomously. This is consistent with the proposal that porc encodes a protein required for $\mathrm{Wg}$ processing. $\mathrm{Wg}$ has been shown to act as a short-range signal in the embryonic epidermis (Vincent and Lawrence 1994). However, Lawrence et al. (1994) discovered that $\mathrm{Wg}$ made in the mesoderm can sustain En expression in the epidermis revealing an in- duction process between germ layers. In such mosaics, where $\mathrm{Wg}$ is produced from the mesoderm, extensive rescue of the ventral epidermis is observed. Similarly, we found that in porc embryonic mosaics, the epidermis can be rescued to a large extent. This probably reflects the ability of $\mathrm{Wg}$ protein to signal across layers from the mesoderm (see Lawrence et al. 1994).

porc encodes a transmembrane protein involved in Wg processing

Because Porc modifies N-linked glycosylation of wild type but not signal sequence-less $\mathrm{Wg}$, we propose that Porc functions along the secretory pathway. This model is consistent with the observation that Porc concentrates at the ER in cultured Drosophila and mouse cell lines. The processing of $\mathrm{Wg}$, expressed in $\mathrm{Kc}$ cells, is unusual in terms of the presence of signal sequence-cleaved but not glycosylated product (form I) at the steady-state level. This type of intermediate never exists because the signal sequence cleavage and glycosylation occur cotranslationally for many secreted glycoproteins. Porc clearly stimulates further processing of this intermediate to 


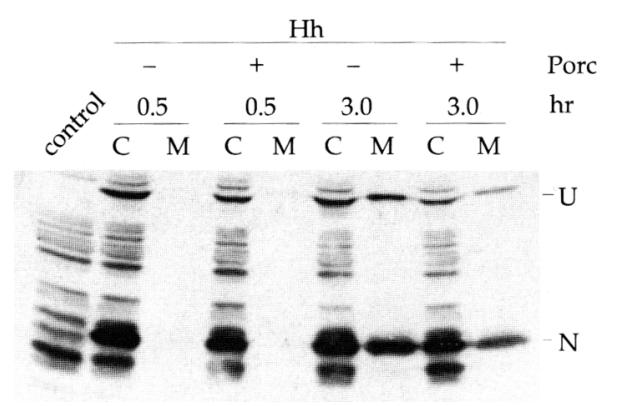

Figure 8. The effect of Porc on Hh processing in cultured cells. Hh protein in the cells lysate $(\mathrm{C})$ and medium $(\mathrm{M})$ at 0.5 and 3.0 hr after heat shock was analyzed by Western blot by use of antibody against $\mathrm{Hh}$ amino-terminal fragment la gift from $\mathrm{P}$. Ingham (Imperial Cancer Research Fund, London, UK); Taylor et al. 1993]. The overexpression of Porc following cotransfection with hs-porc is indicated - and + . Control and $\mathrm{Hh}$ indicate the cells transfected with heat shock plasmid and $h s-h h$, respectively. $\mathrm{U}$ and $\mathrm{N}$ corresponds to a signal sequence cleaved and autoprocessed form, respectively (Lee et al. 1994). The medium contains $0.5 \mathrm{~mm}$ suramin to release $\mathrm{Hh}$ from cell surface.

$\mathrm{N}$-linked glycosylated form. In addition, the form IV Wg is specifically produced in cells expressing both $w g$ and excess porc. There are four potential N-linked glycosylation sites in $\mathrm{Wg}$ and they are probably not all glycosylated under physiological conditions. Because the form IV is not synthesized in the presence of tunicamycin and is sensitive to EndoH, it is likely to contain ectopic $\mathrm{N}$-glycans at sites that are not utilized among four possible glycosylation sites. The modification associated with form IV Wg could be caused by a prolonged retention or conformational change of $\mathrm{Wg}$ in the ER /exposing ectopic N-linked glycosylation site) by excess Porc, supporting a model whereby Porc is involved in the modification of $\mathrm{Wg}$ and localized to the ER.

Porc encodes a transmembrane protein with at least eight membrane-spanning domains and a small hydrophilic region, suggesting that it may form a pore. A possible function of Porc could be to aide Wg to translocate from the cytosol to the ER. In support of this model, we found that $\mathrm{Wg}$, in contrast to yeast $\alpha$ factor and bacterial $\beta$-lactamase (not shown), was not inserted in microsomal membranes when it was translated in vitro, indicating that it requires other factors that are absent in pancreatic microsomes. Porc could be such a factor. Porc may support the translocation of factors necessary for Wg processing in the ER. Such factors may be necessary for changing the environment (for example, $\mathrm{pH}$, ion concentration, and oxydoreduction state) of the ER. It has been reported recently that the influenza virus $M_{2}$ channel modifies the intracellular transport of viral proteins by changing the $\mathrm{pH}$ of Golgi (Sakaguchi et al. 1996). Besides the function of Porc as a channel, it may have direct or indirect roles on $\mathrm{Wg}$ processing in the ER, for example, glycosylation, disulfide bond formation, and folding. We examined the effects of Porc on intra- and interdisulfide bond formation of $\mathrm{Wg}$ by nonreducing and reducing $2 \mathrm{D}$ - gel electrophoresis (Tokida et al. 1990) and found that Porc did not affect these events in cultured cells. Thus, Porc does not appear to act on the numerous cysteine residues that are conserved among different Wnts. To test whether Porc is involved in glycosylation, it will be necessary to analyze the effects of Porc on $\mathrm{Wg}$ in which $\mathrm{N}$-linked glycosylation sites are knocked out.

As shown in Figures 7A and B, forms II and III Wg are secreted by cells expressing $\mathrm{wg}$ alone whereas only form III is secreted by cells expressing both $\mathrm{wg}$ and porc. Because form III is the endogenous $\mathrm{Wg}$ detected in embryos (not shown), form II Wg may be secreted by a default pathway possibly from the ER to the plasma membrane. Its secretion cannot be observed in cells expressing both $w g$ and porc because of its enhanced intracellular processing to Wg forms III and IV. The effect of Porc on the total amount of $\mathrm{Wg}$ secreted in the medium is much less than that on $\mathrm{Wg}$ processing. These results indicate that Wg may require other factors for its efficient secretion in addition to Porc.

\section{Autocrine versus paracrine function of Porc}

A puzzle regarding Porc function in $\mathrm{Wg}$ signaling is whether Porc is involved in $\mathrm{Wg}$ paracrine signaling (i.e., regulation of en expression and formation of naked cuticle). Although porc is required for the maintenance of en expression by $\mathrm{Wg}$, en expression as well as formation of naked cuticle is restored in porc embryos following ectopic expression of $w g$ (Noordermeer et al. 1994; Manoukian et al. 1995). This result suggests that Porc function is not completely essential for $\mathrm{Wg}$ activity in these overexpression assays. This is in contrast to Dsh and Arm, which are required for Wg signaling following ectopic expression (Noordermeer et al. 1994; Manoukian et al. 1995).

Examination of en expression in porc mutant embryos suggests that Porc is required in paracrine $\mathrm{Wg}$ signaling (van den Heuvel et al. 1993). Then why is ectopic expression of $w g$ in porc mutants, by use of either heat shock (Noordermeer et al. 1994) or the Gal4/UAS system (Manoukian et al. 1995), able to restore en expression or generate some naked cuticle? In light of the molecular results presented in this paper, we propose that when $\mathrm{Wg}$ protein is overexpressed, a small amount is secreted perhaps by alternative pathways. Indeed, the existence of multiple secretory routes has been documented, suggesting that this molecular mechanism may happen in Wnt secretion.

Thus, we propose that Porc functions not only in $\mathrm{Wg}$ autocrine but paracrine signaling as well, and when $\mathrm{Wg}$ is overexpressed, some default pathway can get activated.

\section{How specific is Porc to Wg signaling?}

We investigated porc function in the midgut as well as during imaginal phenotypes to determine whether porc is required for distribution of various extracellular signaling molecules. We reasoned that if Porc was required for secretion of other signaling molecules, porc mutant 
animals may exhibit additional mutant phenotypes. Like $\mathrm{Wg}$, Dpp is expressed in the visceral mesoderm but is secreted across tissue layers and is taken up by the adjoining endodermal cells, in which it regulates $l a b$ expression (Panagabian et al. 1990; Reuter et al. 1990). Whereas $w g$ mutants alter the graded expression of Lab in the endodermal nuclei, $d p p$ mutants show no lab expression at all. porc mutants show a pattern of Lab expression very similar to that of $\mathrm{wg}$ embryos. Therefore, it appears that Porc is not required for Dpp function. Further, examination of porc imaginal phenotypes with both molecular and cuticular markers demonstrates the specificity of Porc to Wg signaling. Examination of the imaginal structures fails to implicate a function for Porc in other signaling pathways such as Hh or Dpp. Supporting these in vivo data, we found that Porc does not have any effect on $\mathrm{Hh}$ processing in tissue-cultured cells. Thus, Porc does not appear to be involved in the secretion of other signals.

Our results suggest that Porc does not encode a general requirement for distribution of extracellular signals. However, its possible role in mediating the secretion of other Wnt family members has not been addressed. Other Drosophila Wnt genes have been reported. The processing of DWnt-3 in tissue-cultured cells appears different from that of $\mathrm{Wg}$ because only matured DWnt- 3 is detected at the steady state (Fradkin et al. 1995). Nevertheless, the analysis of the distribution of other Wnts in porc mutants may reveal whether their processing depends on Porc function. In addition to the human MG61 porc-related sequence, recently, we have identified both Xenopus and mouse genes related to porc (T. Kadowaki and N. Perrimon, unpubl.|, raising the exciting possibility that vertebrate proteins may play an analogous function in Wnt proteins processing.

\section{Materials and methods}

\section{porc mutations}

The first porc mutation was isolated in a screen for X-linked zygotic lethal mutations associated with specific maternal-effect lethal phenotypes (Perrimon et al. 1989). Subsequently, three EMS-induced alleles, porc ${ }^{\text {P'B16 }}$ (Perrimon et al. 1989), porc $^{i 8}$ and porc ${ }^{2 E}$, and one gamma-ray induced allele, porc ${ }^{G 18}$ (Eberl et al. 1992), were characterized. In addition, we determined that 1(1)15175 (Ferrus et al. 1990) is also a porc allele. $D p(1 ; 3) / C 153$ is described in Eberl et al. (1992). The five known porc mutations are associated with larval/pupal lethality and all exhibit a fully rescuable maternal effect lethal segmentation phenotype.

All experiments were performed with the porc ${ }^{p B 16}$ allele and then confirmed with at least one more allele (usually porc ${ }^{i 8}$ ). Flies were grown at $25^{\circ} \mathrm{C}$.

\section{Production of porc mutant embryos and examination} of embryos

Germ-line clones of porc alleles were generated with the $O v O^{D 1}$. dominant female sterile mutation as described in Perrimon et al. (1984). Embryos derived from germ-line clones were mounted for cuticle preparation (Wieschaus and Nusslein-Vol- hard 1986) or collected for immunohistochemistry. Lab expression was detected as described by Klingensmith et al. (1994).

\section{Mosaic analyses}

Mosaic patches were detected by the marker $s v b^{Y P 17 b}$ /Gergen and Wieschaus 1986) for embryonic gynandromorphs, and yellow $(y)$, white $(w)$, and forked $\left(f^{36 a}\right)$ (Lindsley and Grell 1968) for adult gynandromorphs and somatic clones. Embryonic gynandromorphs were among the progeny of $r i n g-X / Y$ males crossed to females bearing $s v b$ porc germ-line clones. The ring- $X$ chromosome, a gift from J. Hall (Brandeis University, Waltham, $\mathrm{MA})$, is kept as In(1)dl49, y w lz $/ \mathrm{Yy}^{+}$. Adult gynandromorphs were produced by mating $\mathrm{FM} 7 \mathrm{c} / \mathrm{y} w$ f porc females to ring- $X / Y$ males. Progeny adults and dead pupae were examined for mosaicism (Table 1).

Clones in adult structures were induced by mitotic recombination. $F M 7 c / f^{36 a}$ porc females were mated to $y w / Y$ males and their progeny irradiated at the first to early second instar, at a constant dose of 1000 rads of X-rays. The meiotic location of the $\mathrm{X}$-linked genes $f$ and porc is 56.7 and 59 , respectively. Thus, the occurrence of mitotic crossovers between the two genes is very unlikely. Specimens were mounted in Faure's mountant or dehydrated and mounted in methylsalicylate.

\section{Analyses of imaginal discs and adult phenotypes}

The porc mutant phenotype in the discs and the adult were determined using porc $^{P B 16}$. LacZ-expressing lines were: A101/ TM3 (neuLacZ) (Usui and Kimura 1992), P1394/CyO (E.L. Wilder, unpubl.) apLacZ/CyO (Diaz-Benjumea and Cohen 1993), and H15 (Brook et al. 1993). The latter is a homozygous viable insertion on the second chromosome. P1394 is an insert that produces an aristaless (al) mutant phenotype; however, expression of $L a c Z$ only partially represents the expression pattern of al. Expression of $L a c Z$ in the leg disc resembles al expression, but its expression in the wing disc does not $\{$ E.L. Wilder, unpubl.). To examine the expression of these genes in a porc mutant, porc ${ }^{P B 16} / F M 7$ females were crossed to males of each strain and male progeny were examined by X-Gal staining. Anti-Cut antibody was used as described (Blochlinger et al. 1993).

The adult wing and leg are from porc escaper, which facilitates the examination of the bristles. Pharate adults, which die at late pupal stages, exhibit similar phenotypes. However, examination of mutant wing imaginal discs suggests that their growth can be severely inhibited (not shown), indicating that porc individuals that die at earlier phases may suffer from loss of $w g$ function during limb outgrowth.

\section{RFLP mapping}

The position of the porc gene was determined by restriction fragment length polymorphism (RFLP) mapping (van der Bliek et al. 1991). Two chromosomes were used for this study: y os ${ }^{1}$ which carries a mutation at the outstreched locus located just distal to porc (Eberl et al. 1992), and y w porc ${ }^{P B 16} f^{36 a}$ which carries a porc mutation and the nearby proximal visible marker forked. Southern blots of $y$ os $^{1}, y$ w porc ${ }^{P B 16} f^{36 a} / F M 7$, and $F M 7 / Y$ DNA digested with different restriction enzymes were prepared. These blots were probed with lambda phage DNA covering the os and porc genomic region (a gift from O. Pongs, Zentrum Molekulare Neurobiol, Hamburg, Germany). These analyses allowed us to determine the positions of restriction enzyme sites that are different between the $0 s^{1}$ and porc ${ }^{P B 16}$ chromosomes. Fifteen $y \mathrm{~W} / Y$ wild-type male recombinants were recovered among the progeny of $y \operatorname{os}^{1} / y w$ porc ${ }^{P B 16} f^{36 a}$ females crossed with OreR males. The genomic DNA isolated 
from these male recombinants were analyzed by Southern blots to determine the position of the meiotic recombination events. All recombinants showed the porc ${ }^{P B 16}$ and $o s^{l}$ RFLP in regions beyond os and porc ${ }^{P B 16}$, respectively. In addition, there was a mixture of recombinants carrying different RFLPs in the region between os and porc ${ }^{P B 16}$. The number of the recombinants carrying $\operatorname{porc}^{P B 16}$ RFLP (y-axis) was plotted against the physical map ( $\mathrm{x}$-axis) at the different positions and this formed a line (Fig. 4). The intersection of this line with the $x$-axis defines the approximate position of the porc gene.

\section{Isolation of porc $c D N A s$}

Transcription units located in the porc genomic region were analyzed by Northern blot hybridizations. Poly $(A)^{+}$RNA was prepared from embryos $0-3,1-5$, and 5-9 hr old as described (Herrick et al. 1990) and riboprobes were prepared from plasmids carrying different portions of genomic DNA. This allowed us to determine the size, expression pattern, and transcriptional direction of the various mRNAs present in the region. The breakpoint of $D p(1 ; 3) / C 153$ and DNA alteration of porc ${ }^{G 18}$ was analyzed by Southern hybridization with various DNA probes. porc $^{G 18}$ genomic DNA was digested with four base-cutter enzymes. A 0-3 hr embryonic cDNA library (Brown and Kafatos 1988) was screened with the AccI-SacI genomic DNA fragment, and five positive clones were isolated. They were all identical based on the restriction enzyme analysis. A $2.4-\mathrm{kb}$ cDNA was then sequenced by an automatic DNA sequencer (ABI model 373A). (Note: The complete sequence of the porc cDNA has been deposited in GenBank under accession no. U77310|.

\section{Molecular biology}

The EcoRI-XbaI genomic DNA covering the porc locus was cloned in pCaspeR4 (Thummel and Pirrotta 1992) to generate a genomic porc rescue construct. A heat shock porc construct, hs-porc, was constructed by cloning the porc cDNA in pBluescript KS II following partial digestion by EcoRI and HindIII. The HincII-NotI DNA fragment containing the porc cDNA was then cloned into the HpaI-NotI site of pCaspeR-hs [Thummel and Pirrotta 1992). The injection procedure for generating P-element transformants is described in Spradling (1986).

To generate an HA epitope-tagged porc, the porc cDNA was first cloned into pUC19 followed by destruction of NotI site. New NotI site was then introduced at position 182 or 425 by site-directed mutagenesis. A NotI DNA fragment carrying three HA epitopes from pGTEPl (Tyers et al. 1992) was inserted to these sites. This epitope-tagged cDNA was transferred to pBluescript KS II and cloned into pCaspeR-hs.

Heat shock $w g$ constructs, $h s-w g$ and $h s-w g \Delta N$, were constructed by PCR with wg CDNA as a template and the following primers; primer 1: 5' -CGGGATCCATGGATATCAGCTATATCTT-3', primer 2: 5'-CGGGATCCATGTGCAGCGGCGGCAGCAGTCTCAGC-3', and primer 3: 5'-CGAGGCCTTTACAGACACGTGTAGATGA-3'. Primer $1 / 3$ and $2 / 3$ produces wild-type $w g$ and mutant $w g$, respectively. PCR products were then cloned in BgIII-StuI site of pCaspeR-hs after BamHI and Stul digestion.

\section{RNA injection}

For injections of RNAs in early embryos, capped RNA was prepared with SP6 and T3 RNA polymerase from the linearized plasmids NB40 and pBluescript KS II, respectively. NB40 contains the wild-type porc sequence and pBluescript KS II contains the porc-HA sequence. The RNA was dissolved in an injection buffer and injected into precellular blastoderms as described (Schneider et al. 1991). The embryos were derived from females with homozygous $s v b^{Y P 17 b}$ porc ${ }^{P B 16}$ germ-line clones crossed with wild-type males. porc mutant embryos rescued as a result of the RNA injection showed the $s v b$ phenotype. The injected embryos were allowed to develop at $18^{\circ} \mathrm{C}$ under halocarbon oil and their cuticles examined after 3 days. In these experiments, germ-line clones of porc were generated with the FLP-DFS technique (Chou and Perrimon 1992) as described (Siegfried et al. 1994). Of 198 embryos injected, 28 were rescued to various extent.

\section{In situ hybridization}

Overnight collection of OreR embryos were subjected to standard in situ hybridization by use of sense (negative control) and antisense probes. The probes were generated from a plasmid carrying the porc cDNA Sacl-Xhol fragment by PCR in the presence of digoxigenin-16-dUTP. The hybridization signal was detected by alkaline phosphatase-conjugated antidigoxigenin antibody and NBT/X-phosphate complex (Boehringer).

\section{Transfection of Kc cells and indirect immunofluorescence}

$\mathrm{Kc}$ cells were maintained in HYQ-CCM3 medium (Hyclone) and inoculated in six-well plates at $50 \%$ confluency. They were transfected with $2.5 \mu \mathrm{g}$ hs -porc HA plasmid with DOTAP transfection reagent (Boehringer) for $48 \mathrm{hr}$ at $25^{\circ} \mathrm{C}$. Cells were then heat shocked at $37^{\circ} \mathrm{C}$ for $45 \mathrm{~min}$ followed by attachment to poly-L-lysine coated eight-well chamber slides. After 90 min at $25^{\circ} \mathrm{C}$, they were fixed with $4 \%$ paraformaldehyde in PBS for 15 min at room temperature. Following cell permeabilization with $0.5 \%$ TX -100 in PBS for 5 min, cells were blocked with PHT (PBS containing 5\% horse serum and $0.1 \%$ Tween 20 ) for $1 \mathrm{hr}$. They were then incubated with $5 \mu \mathrm{g} / \mathrm{ml}$ of $12 \mathrm{CA} 5$ monoclonal antibody directed against the HA epitope in PHT for $2 \mathrm{hr}$ followed by multiple washes with PT (PBS with $0.1 \%$ Tween 20) for $1 \mathrm{hr}$. The FITC-conjugated antimouse antibody was used at a dilution of 1:200 for 1 hr followed by 3 washes each with PT and PT containing $0.3 \mathrm{M} \mathrm{NaCl}$ for I hr. Cells were also stained with $1 \mu \mathrm{g} / \mathrm{ml}$ DAPI for $5 \mathrm{~min}$ and mounted with SlowFade reagent (Molecular Probes).

To analyze the processing of $\mathrm{Wg}$, Kc cells were transfected with $h s-w g$ or $h s-w g \Delta N$ alone or along with $h s$-porc plasmid as above. After heat shock, new medium containing $0.5 \mathrm{~mm}$ suramin was added, then incubated at $25^{\circ} \mathrm{C}$. The cell lysate and medium was recovered at 0.5 and $3 \mathrm{hr}$ after heat shock followed by Western blot analysis with rabbit anti-Wg antibody $(1000$ dilution). The processing of $\mathrm{Hh}$ in $\mathrm{Kc}$ cells was examined as above except that a $h s-h h$ plasmid and rabbit anti-Hh antibody (2000 dilution/ were used.

\section{Tunicamycin, pulse-chase, and EndoH treatment}

Tunicamycin was added to the cells $3 \mathrm{hr}$ prior to heat shock and present throughout experiment at $25 \mu \mathrm{g} / \mathrm{ml}$. The cell lysate was analyzed by Western blot with anti-Wg antibody. The transfected cells with indicated plasmids were labeled at $30 \mathrm{~min}$ after heat shock with $250 \mu \mathrm{Ci}$ of Pro-mix $\left({ }^{35} \mathrm{~S}\right.$-Cys / Met mixture, Amersham) in methionine-free $\mathrm{M} 3$ medium containing $0.5 \mathrm{~mm}$ suramin for $1 \mathrm{hr}$ followed by 0 and $3 \mathrm{hr}$ chase by adding cold methionine at a final concentration of $0.25 \mathrm{~g} / 1$. The cell lysate and medium prepared in RIPA buffer was immunoprecipitated with anti-Wg antibody and protein A-Sepharose. Immunoprecipitates were analyzed with $10 \%$ SDS-PAGE and the radioactivity of individual $\mathrm{Wg}$ form in the medium was measured by 
Bio-Image Analyzer, BAS2000 (FUII). To test for EndoH sensitivity, transfected cells were labeled for $5 \mathrm{hr}$ as above except that suramin was not included in the medium. The immunoprecipitates from cell lysates were suspended in $0.1 \mathrm{M}$ sodium phosphate buffer, at $\mathrm{pH} 6.0$ with $0.1 \%$ SDS, then boiled for 5 min. They were then treated with 2 microUnits of EndoH or buffer in the presence of $1 \mathrm{~mm}$ PMSF for $15 \mathrm{hr}$ at $37^{\circ} \mathrm{C}$.

\section{Acknowledgments}

We thank O. Pongs and T. Tabata for providing us with DNA covering the porc region and $h s-h h$ construct, respectively; J. Hall and R. Nusse for fly stocks; L. Mathies, C. Goodman, P. Ingham, and $\mathrm{S}$. Yanagawa for anti-Lab, anti-En, anti-Hh, and anti-Wg antibody, respectively; T. Rapoport and E. Hartmann for help with the Porc sequence analysis; S. Cumberledge for communicating results prior to publication; R. Nusse for helpful discussions; Y. Kitagawa for advice on $\mathrm{Wg}$ processing; and C. Kumagai for technical assistance. T.K. is supported by Research Fellowships from the Japan Society for the Promotion of Science for Young Scientists. E.W. was supported by a postdoctoral fellowship from the National Institutes of Health. K.Z. was partially supported by a summer undergraduate internship from the Genetics Society of Amcrica. J.K. was a predoctoral fellow of the Lucille P. Markey Charitable Trust. N.P. is an associate investigator of the Howard Hughes Medical Institute.

The publication costs of this article were defrayed in part by payment of page charges. This article must therefore be hereby marked "advertisement" in accordance with 18 USC section 1734 solely to indicate this fact.

\section{References}

Ashcroft, F.M. and J. Röper. 1993. Transporters, channels and human disease. Curr. Opin. Cell Biol. 5: 677-683.

Bejsovec, A. and E. Wieschaus. 1993. Segment polarity gene interactions modulate epidermal patterning in Drosophila embryos. Development 119: 501-517.

Bhanot, P., M. Brink, C. Harryman Samos, J.-C. Hsieh, Y. Wang, J.P. Macke, D. Andrew, J. Nathans, and R. Nusse. 1996. A new member of the frizzled family from Drosophila functions as a Wingless receptor. Nature 382: 225-230.

Blochlinger, K., L.Y. Jan, and Y.N. Jan. 1993. Postembryonic expression of cut, a locus regulating sensory organ identity in Drosophila. Development 117: 441-450.

Brook, W.J., L.M. Ostafichuk, J. Piorecky, M.D. Wilkinson, D.J. Hodgetts, and M.A. Russell. 1993. Gene expression during imaginal disc regeneration detected using enhancer-sensitive P-elements. Development 117: 1287-1297.

Brown, N.H. and F.C. Kafatos. 1988. Functional cDNA libraries from Drosophila embryos. I. Mol. Biol. 203: 425-437.

Campbell, G., T. Weaver, and A. Tomlinson. 1993. Axis specification in the developing Drosophila appendage: The role of wingless, decapentaplegic, and the homeobox gene aristaless. Cell 74: 1113-1123.

Chou, T.B. and N. Perrimon. 1992. Use of a yeast site-specific recombinase to produce female germline chimeras in Drosophila. Genetics 131: 643-653.

Couso, J.P., M. Bate, and A. Martinez-Arias. 1993. A winglessdependent polar coordinate system in Drosophila imaginal discs. Science 259: 484-489.

Couso, J.P., S.A. Bishop, and A. Martinez-Arias. 1994. The wingless signalling pathway and the patterning of the wing margin in Drosophila. Development 120: 621-636.

Diaz-Benjumea, F.J. and S.M. Cohen. 1993. Interaction between dorsal and ventral cells in the imaginal disc directs wing development in Drosophila. Cell 75: 741-752.

DiNardo, S., E. Sher, J. Heemskerk-Jongens, J.A. Kassis, and P.H. O'Farrell. 1988. Two-tiered regulation of spatially patterned engrailed gene expression during Drosophila embryogenesis. Nature 332: 604-609.

Eberl, D., L. Perkins, M. Englestein, A. Hilliker, and N. Perrimon. 1992. Genetics of the polytene chromosome region 17A-C. Genetics 127: 357-371.

Eisenberg, D., R.M. Weiss, and T.C. Terwilliger. 1984. The hydrophobic moment detects periodicity in protein hydrophobicity. Proc. Natl. Acad. Sci. 81: 140-144.

Ferrus, A., S. Llamazares, J. de la Pompa, M. Tanouye, and O. Pongs. 1990. Genetic analysis of the Shaker complex of Drosophila melanogaster. Genetics 125: 383-398.

Fradkin, L.G., J.N. Noordermeer, and R. Nusse. 1995. The Drosophila Wnt protein DWnt-3 is a secreted glycoprotein localized on the axon tracts of the embryonic CNS. Dev. Biol. 168: 202-213.

Gergen, P. and E.H. Wieschaus. 1986. Localized requirements for gene activity in segmentation of Drosophila embryos: Analysis of armadillo, fused, giant and unpaired mutations in mosaic cmbryos. Roux's Arch. Dev. Biol. 195: 49-62.

Gonzalez, F., L. Swales, A. Bejsovec, H. Skaer, and A. MartinezArias. 1991. Secretion and movement of the wingless protein in the epidermis of the Drosophila embryo. Mech. Dev. 35: $43-54$.

Griffith, J.K., M.E. Baker, D.A. Rouch, M.G.P. Page, R.A. Skurray, I.T. Paulsen, K.F. Chater, S.A. Baldwin, and P.J.F. Henderson. 1992. Membrane transport proteins: Implications of sequence comparisons. Curr. Opin. Cell Biol. 4: 684-695.

Hartmann, E., T.A. Rapoport, and H.F. Lodish. 1989. Predicting the orientation of eukaryotic membrane spanning proteins. Proc. Nat1. Acad. Sci. 86: 5786-5790.

Henderson, P.J.F. 1993. The 12-transmembrane helix transportcrs. Curr. Opin. Cell Biol. 5: 708-721.

Herrick, D., R. Parker, and A. Jacobson. 1990. Identification and comparison of stable and unstable mRNAs in Saccharomyces cerevisiae. Mol. Cell. Biol. 10: 2269-2284.

Hooper, J.W. 1994. Distinct pathways for autocrine and paracrine Wingless signalling in Drosophila embryos. Nature 372: 461-464.

Immergluck, K., P. Lawrence, and M. Bienz. 1990. Induction across germ layers in Drosophila mediated by a genetic cascade. Cell 62: 261-268.

Klingensmith, J. and R. Nusse. 1994. Signaling by Wingless in Drosophila. Dev. Biol. 166: 396-414.

Klingensmith, I., R. Nusse, and N. Perrimon. 1994. The Drosophila polarity gene dishevelled encodes a novel protein required for response to the wingless signal. Genes \& Dev. 8: $118-130$.

Kyte, J. and R.F. Doolittle. 1982. A simple method for displaying the hydopathic character of a protein. J. Mol. Biol. 157: 105132.

Lawrence, P.A., P. Johnston, and J.-P. Vincent. 1994. wingless can bring about a mesoderm-to-ectoderm induction in Drosophila embryos. Development 120: 3355-3359.

Lee, J.J., S.C. Ekker, D.P. von Kessler, J.A. Porter, B.I. Sun, and P.A. Beachy. 1994. Autoproteolysis in hedgehog protein biogenesis. Science 266: 1528-1537.

Lindsley, D.L. and E.H. Grell. 1968. Genetic variations of Drosophila melanogaster. Carnegie Institution of Washington, Washington, D.C.

Manoukian, A.S., K. Yoffe, E.L. Wilder, and N. Perrimon. 1995. The porcupine gene is required for wingless autoregulation in Drosophila. Development 121: 4037-4044. 
Martinez-Arias, A., N. Baker, and P.W. Ingham. 1988. Role of segment polarity genes in the definition and maintenance of cell states in the Drosophila embryo. Development 103: 157-170.

Nathans, J., D. Thomas, and D.S. Hogness. 1986. Molecular genetics of human color vision: The genes encoding blue, green, and red pigments. Science 232: 193--202.

Noordermeer, J., J. Klingensmith, N. Perrimon, and R. Nusse. 1994. dishevelled and armadillo are essential components of the wingless signaling pathway in Drosophila. Nature 367: 80-83.

Panagabian, G., R. Reuter, M. Scott, and F.M. Hoffman. 1990. A Drosophila growth factor homolog, decapentaplegic, regulates homeotic gene expression within and across germ layers during midgut morphogenesis. Development 110: 10411050.

Perrimon, N. 1996. Serpentine proteins slither into the Wingless and Hedgehog fields. Cell 86: 513-516.

Perrimon, N., L. Engstrom, and A.P. Mahowald. 1984. The effects of zygotic lethal mutations on female germ-line functions in Drosophila. Dev. Biol. 105: 404-414.

- 1989. Zygotic lethals with specific maternal effect phenotypes in Drosophila melanogaster: I. Loci on the X-chromosome. Genetics 121: 333-352.

Phillips, R.G. and J.R.S. Whittle. 1993. wingless expression mediates determination of peripheral nervous system elements in late stages of Drosophila wing disc development. Development 118: 427-438.

Rao, J.K.M. and P. Argos. 1986. A conformational preference parameter to predict helices in integral membrane proteins. Biochim. Biophys. Acta 869: 197-214.

Reuter, R., G.E.F. Panganiban, F.M. Hoffman, and M.P. Scott. 1990. Homeotic genes regulate the spatial expression of putative growth factors in the visceral mesoderm of Drosophila embryos. Development 110: 1031-1040.

Sakaguchi, T., G.P. Leser, and R.A. Lamb. 1996. The ion channel activity of the influenza virus $M_{2}$ protein affects transport through the Golgi apparatus. I. Cell Biol. 133: 733-747.

Schneider, D.S., K.L. Hudson, T.-Y. Lin, and K.V. Anderson. 1991. Dominant and recessive mutations define functional domain of Toll, a transmembrane protein required for dorsal-ventral polarity in the Drosophila embryo. Genes \& Dev. 5: 797-807.

Siegfried, E. and N. Perrimon. 1994. Drosophila Wingless: A paradigm for the function and mechanism of Wnt signaling. Bioessays 16: 195-404.

Siegfried, E., E. Wilder, and N. Perrimon. 1994. Components of wingless signaling in Drosophila. Nature 367: 76-80.

Spradling, A. 1986. P-element mediated transformation. In Drosophila: A practical approach (ed. D.B. Roberts), ILR Press, Oxford, UK.

Struhl, G. and K. Basler. 1993. Organizing activity of Wingless protein in Drosophila. Cell 72: 527-540.

Taylor, A.M., Y. Nakano, J. Mohler, and P.W. Ingham. 1993. Contrasting distributions of patched and hedgehog proteins in the Drosophila embryo. Mech. Dev. 42: 89-96.

Thummel, C.S. and V. Pirrotta. 1992. New pCaSpeR P element vectors. Drosophila Inf. Service 71: 150.

Tokida, Y., Y. Aratani, A. Morita, and Y. Kitagawa. 1990. Production of two variant laminin forms by endothelial cells and shift of their relative levels by angiostatic steroids. $I$. Biol. Chem. 265: 18123-18129.

Tyers, M., G. Tokiwa, R. Nash, and B. Futcher. 1992. The Cln3$\mathrm{Cdc} 28$ kinase complex of $S$. cerevisiae is regulated by proteolysis and phosphorylation. EMBO J. 11: 1773-1784.

Unwin, N. 1989. The structure of ion channels in membranes of excitable cells. Neuron 3: 665-676.

Usui, K. and K.-I. Kimura. 1992. Sensory mother cells are selected from among mitotically quiescent cluster of cells in the wing disc of Drosophila. Development 116: 601-610.

van den Heuvel, M., C. Harryman-Samos, J. Klingensmith, N. Perrimon, and R. Nusse. 1993. Mutations in the segment polarity genes wingless and porcupine impair secretion of the wingless protein. EMBO. I. 12: 5293-5303.

van den Heuvel, M., R. Nusse, P. Johnston, and P. Lawrence. 1989. Distribution of the wingless gene product in Drosophila embryos: A protein involved in cell-cell communication. Cell 59: 739-749.

van der Bliek, A.M. and E.M. Meyerowitz. 1991. Dynamin-like protein encoded by the Drosophila shibire gene associated with vesicular traffic. Nature 351: 411-414.

Vincent, I.P. and P.A. Lawrence. 1994. Drosophila wingless sustains engrailed expression only in adjoining cells: Evidence from mosaic embryos. Cell 77: 909-915.

Wieschaus, E. and C. Nusslein-Volhard. 1986. Looking at embryos. In Drosophila: A practical approach led. D.B. Roberts), IRL Press, Oxford, UK.

Yoffe, K., A. Manoukian, E. Wilder, A. Brand, and N. Perrimon. 1995. Evidence for engrailed-independent wingless autoregulation in Drosophila. Dev. Biol. 170: 636-650.

Zalokar, M., I. Erk, and P. Santamaria. 1980. Distribution of ring-X chromosomes in the blastoderm of gynandromorphic Drosophila melanogaster. Cell 19: 133-141.

Zecca, M., K. Basler, and G. Struhl. 1995. Sequential organizing activities of engrailed, hedgehog, and decapentaplegic in the Drosophila wing. Development 121: 2265-2278. 


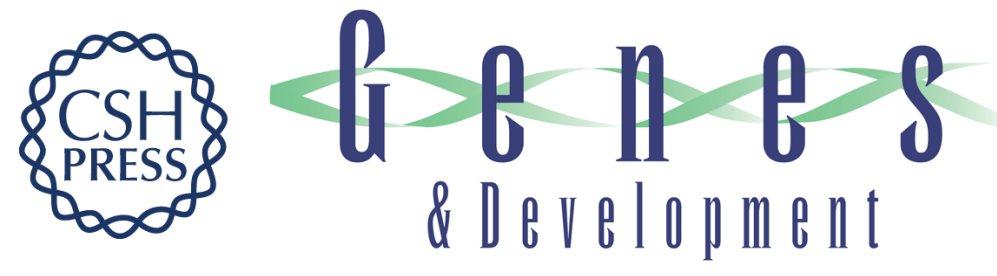

\section{The segment polarity gene porcupine encodes a putative multitransmembrane protein involved in Wingless processing.}

T Kadowaki, E Wilder, J Klingensmith, et al.

Genes Dev. 1996, 10:

Access the most recent version at doi:10.1101/gad.10.24.3116

References This article cites 58 articles, 25 of which can be accessed free at:

http://genesdev.cshlp.org/content/10/24/3116.full.html\#ref-list-1

License

Email Alerting

Service

Receive free email alerts when new articles cite this article - sign up in the box at the top right corner of the article or click here.

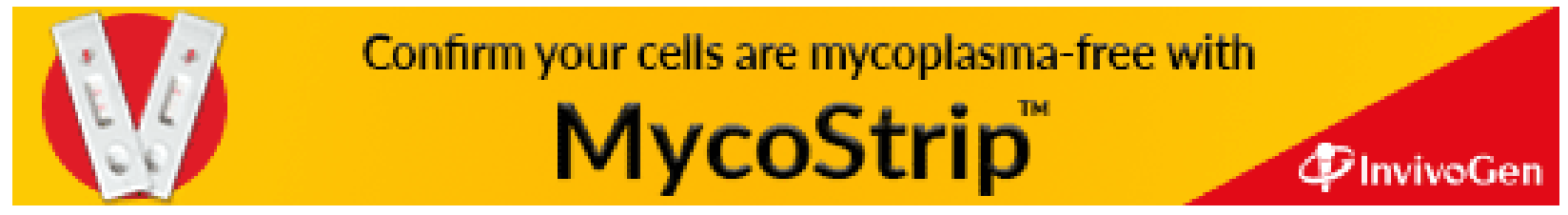

